\title{
The use status of anticoagulation drugs for inpatients with nonvalvular atrial fibrillation in Southwest China
}

\author{
Huan Jie Zheng \\ Shu Kun Ouyang \\ Yue Zhao \\ Kai Lu \\ Su Xin Luo \\ Hua Xiao
}

Department of Cardiology, The First Affiliated Hospital of Chongqing Medical University, Chongqing,

People's Republic of China
Correspondence: Hua Xiao

Department of Cardiology, The First

Affiliated Hospital of Chongqing Medical

University, No.I Youyi Road, Yuzhong,

Chongqing 400016, People's Republic of

China

Tel $+86238901 \quad 1565$

Fax +862389011565

Email xiaoheart1974@163.com
This article was published in the following Dove Press journal:

International Journal of General Medicine

3 March 2017

Number of times this article has been viewed

Background: Oral anticoagulants (OACs) are effective for the prophylaxis of stroke in patients with atrial fibrillation (AF). This cross-sectional study aimed to investigate the status of anticoagulation treatment for hospitalized AF patients in Southwest China.

Methods: A total of 4760 hospitalized patients with AF were enrolled from 21 hospitals in Chongqing city from January 1 to December 31, 2013.

Results: Among the enrolled patients, 3785 were diagnosed with nonvalvular AF. These patients had a mean age of $74.4 \pm 10.1$ years. The mean $\mathrm{CHADS}_{2}$ score of all subjects was $2.60 \pm 1.34$, and $80.7 \%$ of the patients had $\mathrm{CHADS}_{2} \geq 2$. The use rate of OACs was only $11.5 \%$ for patients with a high risk for stroke $\left(\mathrm{CHADS}_{2} \geq 2\right)$ and was much lower in patients from the second-level hospitals than in patients from the third-level hospitals $(5.8 \%$ vs. $16.9 \%, P<0.001)$. The leading reason for the underuse of OACs in high-risk patients was physician's nonfeasance.

Conclusion: This study demonstrated that the underuse of anticoagulation therapy in hospitalized patients with nonvalvular AF was particularly serious in Southwest China, especially in the second-level hospitals. Urgent and effective measures are desperately needed to improve this alarming situation in China.

Keywords: atrial fibrillation, anticoagulation therapy, oral anticoagulant, antiplatelet therapy, international normalized ratio

\section{Introduction}

Atrial fibrillation (AF) is one of the most common arrhythmias in China and worldwide. Approximately $1 \%$ of the total population is estimated to suffer from AF worldwide, and its prevalence rate has a tendency to rise with increasing age. ${ }^{1}$ In China, morbidity due to AF is as high as $0.77 \%$, and $7.5 \%$ of these subjects are $>80$ years of age. ${ }^{2} \mathrm{AF}$ is one of the important causes of stroke. The Framingham study indicated that AF could raise the risk of stroke by $>5$-fold, compared with subjects without $\mathrm{AF}^{3}$ An overwhelming number of studies have demonstrated that anticoagulation therapy can remarkably reduce the incidence of stroke in AF patients. ${ }^{4-6} \mathrm{~A}$ meta-analysis ${ }^{4}$ of 21 studies confirmed that the use of adjusted-dose warfarin reduced the risk of stroke by $\sim 60 \%$ and all-cause death by $\sim 25 \%$, compared with subjects without antithrombotic treatment. However, the narrow therapeutic window and broad interactions with other drugs and foods have hampered the widespread use of warfarin. Consequently, the proportion of AF patients treated for anticoagulation was only $2.7 \%$ in China according to a nationwide survey carried out in 2003. Even worse, more than one-third of these patients were treated with only aspirin, which is not as effective in preventing stroke in AF patients. During the latest 10 years, the anticoagulant use rate has grown by $28.7 \%$; however, the rate is 
still far lower than the rates in North America, Europe, and even other Asian countries., ${ }^{2,7-10}$ Reasonable anticoagulant therapy is of great importance to improve the quality of life and the long-term prognosis of AF patients. Therefore, in this study, we investigated the status of anticoagulation therapy for inpatients with nonvalvular AF in Chongqing, which is the largest city in Southwest China, in order to guide and optimize the anticoagulation management of AF.

\section{Methods}

\section{Study population}

\section{Participating institutions}

The hospital classification management system in China is different from the health care systems in other countries. In China, hospitals are divided into three different levels (ie, firstlevel health care institutes [primary hospitals], second-level health care institutes [secondary hospitals], and third-level health care institutes [tertiary hospitals]) according to their different functions and tasks. Secondary and tertiary hospitals are usually the medical centers of a county or a city and are responsible for the diagnosis and treatment of an overwhelming majority of AF patients. Based on the above rationale, we included secondary and tertiary hospitals in this study.

Chongqing city is the biggest municipality directly under the central government and is one of the central cities in Southwest China. Chongqing city covers an area of 82,402.95 $\mathrm{km}^{2}$; in 2013, it contained 38 administrative regions, including 19 districts, 15 counties, and 4 autonomous counties. Its population was 29.7 million and it had 18 tertiary hospitals and 37 secondary hospitals in 2013. Twenty-one hospitals ( 9 tertiary hospitals and 12 secondary hospitals) were randomly chosen by multistage random sampling in the current study.

\section{Inclusion and exclusion criteria}

Patients (aged $\geq 18$ years) admitted to the 21 selected hospitals between January and December 2013 with a diagnosis of AF were enrolled in this study. The diagnosis of AF was based on a 12-lead electrocardiogram, Holter electrocardiogram, clinical diagnosis, or relevant medical records. Information from rehospitalized individuals was recorded again if any one of the four factors $\left(\mathrm{CHADS}_{2}\right.$ score [congestive heart failure, hypertension, age $\geq 75$, diabetes, stroke $\{$ double $\}] \mathrm{CHA}_{2} \mathrm{DS}_{2}$-VASc score [congestive heart failure, hypertension, age $\geq 75$ \{double\}, diabetes, stroke $\{$ double\}, vascular disease, age 65-74, and sex \{female\}] HAS-BLED score [hypertension, abnormal renal/liver function, stroke, bleeding history or predisposition, labile INR, elderly $\{>65$ years $\}$, drugs/alcohol concomitantly], or antithrombotic scheme) differed from the previous entry.
Patients who had participated in clinical research related to interventional treatment were excluded.

\section{Ethical statements}

This study was in accordance with the Declaration of Helsinki. Due to the retrospective nature of the study, informed consent was not obtained. In view of this, this study was approved by the Medical Ethics of Chongqing Municipal Health and the Family Planning Commission without the informed consent.

\section{Data collection}

Clinical information for the included patients was collected from the electronic medical record system, including the date of birth, gender, type of AF, concomitant diseases, history of thromboembolism, administration of antithrombotic agents during hospitalization, and reasons for not prescribing anticoagulant drugs. Both the $\mathrm{CHADS}_{2}$ and $\mathrm{CHA}_{2} \mathrm{DS}_{2}-\mathrm{VASc}$ scores were calculated to develop stroke risk stratification schemes that divided the risk of thromboembolism into low $\left(\mathrm{CHADS}_{2} / \mathrm{CHA}_{2} \mathrm{DS}_{2}-\mathrm{VASc}\right.$ score $\left.=0\right)$, moderate $\left(\mathrm{CHADS}_{2} /\right.$ $\mathrm{CHA}_{2} \mathrm{DS}_{2}-\mathrm{VASc}$ score $\left.=1\right)$, and high $\left(\mathrm{CHADS}_{2} / \mathrm{CHA}_{2} \mathrm{DS}_{2}-\right.$ VASc score $\geq 2$ ) risk strata. The HAS-BLED score was calculated to develop bleeding risk stratification schemes that divided the risk of bleeding into low (HAS-BLED score $<3$ ) and high (HAS-BLED score $\geq 3$ ) risk strata. For warfarin-treated AF patients, the last international normalized ratio (INR) before their discharge was recorded and used to categorize the INR values into four strata: $<1.50,1.50-1.99$, 2.00-3.00, and $>3.00$.

\section{Definitions}

Nonvalvular AF (NVAF) is restricted to cases in which the rhythm disturbance occurs in the absence of rheumatic mitral valve disease, a prosthetic heart valve, or mitral valve repair ${ }^{11}$ The diagnosis of heart failure was made by two attending physicians together according to the symptoms, signs, blood brain natriuretic peptide or $\mathrm{N}$-terminal pro-brain natriuretic peptide, and Doppler echocardiography. Disagreements were resolved by a third senior physician. Ischemic stroke was defined as a focal neurologic deficit diagnosed by a neurologist or manifested by computed tomography or magnetic resonance imaging. The diagnosis of coronary heart disease was primarily based on clinical symptoms or was manifested by coronary artery computed tomography or coronary angiography. Chronic kidney disease was diagnosed if there was persistent proteinuria or if the estimated glomerular filtration rate was $<60 \mathrm{~mL} / \mathrm{min} / 1.73 \mathrm{~m}^{2}$ for $>3$ months. 


\section{Statistical analysis}

All statistical analyses were performed using Statistical Package for the Social Sciences 20.0 (IBM Corporation, Armonk, NY, USA). Continuous variables were presented as the mean with standard deviation (SD) and categorical variables as percentages. To assess baseline characteristic differences between the NVAF patients in the secondary and tertiary hospital groups, Pearson's $\chi^{2}$ test or Fisher's exact test was used to compare categorical variables and Student's $t$-test to compare continuous variables. Mann-Whitney $U$ test was used to compare the average values of the $\mathrm{CHADS}_{2}, \mathrm{CHA}_{2} \mathrm{DS}_{2}-\mathrm{VASc}$, and HAS-BLED scores. For all analyses, a two-sided probability value $<0.05$ was considered statistically significant.

\section{Results}

A total of $4760 \mathrm{AF}$ inpatients were enrolled in the present study, of which 3785 (79.5\%) were NVAF patients. In the present study, we primarily present the data from the NVAF inpatients.

\section{Baseline characteristics of all patients}

The baseline characteristics of all NVAF inpatients are summarized in Table 1. The mean age was $74.4 \pm 10.1$ years, and more than half of all patients $(56.1 \%)$ were aged $\geq 75$ years. In contrast to other studies, more females (55.2\%) were enrolled in this investigation. With regard to the type of AF, $27.3 \%$ of the cases were paroxysmal AF and $72.7 \%$ were persistent or permanent AF. The major concomitant diseases were coronary artery disease $(68.4 \%)$, myocardial infarction $(7.5 \%)$, heart failure (57.3\%), hypertension (57.1\%), stroke (19.4\%), diabetes (16.8\%), and chronic kidney disease (11.2\%). Of all patients, $21.9 \%$ had suffered from thromboembolic events. Only $11.5 \%$ of the total patients had been prescribed oral anticoagulants (OACs), 32.4\% had taken aspirin, and 27.1\% received no antithrombotic drugs. In this study, the mean INR of the patients using warfarin was $1.48 \pm 0.66$. More than $60 \%$ of the warfarin-treated patients had an INR $<1.50$, whereas $16.9 \%$ had an INR between 1.50 and 1.99 , and only $13.5 \%$ had an INR between 2.00 and 3.00 .

\section{$\mathrm{CHADS}_{2}, \mathrm{CHA}_{2} \mathrm{DS}_{2}-\mathrm{VASc}$, and HAS- BLED scores}

Among all patients, the mean $\mathrm{CHADS}_{2}, \mathrm{CHA}_{2} \mathrm{DS}_{2}$-VASc, and HAS-BLED scores were 2.60 $1.34,3.30 \pm 1.54$, and $1.75 \pm 1.04$, respectively. Figure 1 shows a histogram of the $\mathrm{CHADS}_{2}, \mathrm{CHA}_{2} \mathrm{DS}_{2}-\mathrm{VASc}$, and HAS-BLED scores. The percentages of patients with CHADS 2 scores of $0,1,2,3,4$, 5 , and 6 were $4.0 \%, 15.3 \%, 33.5 \%, 23.8 \%, 13.1 \%, 8.5 \%$, and $1.9 \%$, respectively. A total of $80.7 \%$ of the NVAF patients had a CHADS $_{2}$ score $\geq 2$ and $<30 \%$ had a HAS-BLED score $\geq 3$.
Table I Baseline characteristics

\begin{tabular}{|c|c|}
\hline Variable & All patients $(N=3785)$ \\
\hline Age, mean (SD), years & $74.4 \pm 10.1$ \\
\hline \multicolumn{2}{|l|}{ Age, years } \\
\hline$<65$ & $583(15.4)$ \\
\hline $65-74$ & $1078(28.5)$ \\
\hline $75-79$ & $812(21.5)$ \\
\hline$\geq 80$ & $1312(34.7)$ \\
\hline Range & $21-101$ \\
\hline \multicolumn{2}{|l|}{ Gender } \\
\hline Male & $1696(44.8)$ \\
\hline Female & $2089(55.2)$ \\
\hline \multicolumn{2}{|l|}{ Classification of AF } \\
\hline Paroxysmal AF & $1034(27.3)$ \\
\hline Persistent/permanent AF & $275 \mathrm{I}(72.7)$ \\
\hline History of thrombosis & $829(21.9)$ \\
\hline Stroke & 734 (19.4) \\
\hline TIA & $59(1.6)$ \\
\hline SEE & $60(1.6)$ \\
\hline Left atrial thrombi & $18(0.5)$ \\
\hline \multicolumn{2}{|l|}{ Anticoagulant strategy } \\
\hline None & $1024(27.1)$ \\
\hline OAC & $437($ (II.5) \\
\hline Warfarin & 433 (II.4) \\
\hline Factor $\mathrm{Xa}$ /direct thrombin inhibitor & $4(0.1)$ \\
\hline Antiplatelet & $2191(57.9)$ \\
\hline Aspirin & $1226(32.4)$ \\
\hline Clopidogrel & $579(\mid 5.3)^{\prime}$ \\
\hline Aspirin plus clopidogrel & $374(9.9)$ \\
\hline Other antiplatelet agents $\mathrm{a}^{\mathrm{a}}$ & $12(0.3)$ \\
\hline Others & $133(3.5)$ \\
\hline LMWH & $44(1.2)$ \\
\hline Fondaparinux sodium & $4(0.1)$ \\
\hline \multicolumn{2}{|c|}{ Medical history } \\
\hline Coronary artery disease & $2589(68.4)$ \\
\hline Previous myocardial infarction & $282(7.5)$ \\
\hline Hypertension & $2160(57.1)$ \\
\hline Heart failure & $2170(57.3)$ \\
\hline Diabetes mellitus & $637(16.8)$ \\
\hline Chronic kidney disease & 424 (1 I.2) \\
\hline COPD & $254(6.7)$ \\
\hline Cancer & $82(2.2)$ \\
\hline \multicolumn{2}{|l|}{$\begin{array}{l}\text { Risk scores } \\
\text { CHADS }_{2}\end{array}$} \\
\hline Mean \pm SD & $2.60 \pm 1.34$ \\
\hline 0 & $152(4.0)$ \\
\hline I & $578(15.3)$ \\
\hline$\geq 2$ & $3055(80.7)$ \\
\hline \multicolumn{2}{|l|}{ CHA,DS-VASc } \\
\hline Mean \pm SD & $3.30 \pm 1.54$ \\
\hline 0 & $87(2.3)$ \\
\hline I & $332(8.8)$ \\
\hline$\geq 2$ & $3366(88.9)$ \\
\hline \multicolumn{2}{|l|}{ HAS-BLED } \\
\hline Mean \pm SD & $1.75 \pm 1.04$ \\
\hline 0 & $322(8.5)$ \\
\hline I & $1375(36.3)$ \\
\hline 2 & 1275 (33.7) \\
\hline$\geq 3$ & $813(2 \mid .5)$ \\
\hline \multicolumn{2}{|l|}{ INR } \\
\hline Mean \pm SD & $1.48 \pm 0.66$ \\
\hline$<1.50$ & $228(65.3)$ \\
\hline $1.50-1.99$ & $59(16.9)$ \\
\hline $2.00-3.00$ & $47(13.5)$ \\
\hline$>3.00$ & $15(4.3)$ \\
\hline
\end{tabular}

Notes: Data are presented as number (\%) or mean \pm SD. ${ }^{2}$ Cilostazol and cilostazol plus clopidogrel.

Abbreviations: AF, atrial fibrillation; COPD, chronic obstructive pulmonary disease; INR, international normalized ratio; LMWH, low-molecular-weight heparin OAC, oral anticoagulant; SD, standard deviation; SEE, systemic embolic event; TIA, transient ischemic attack. 
A

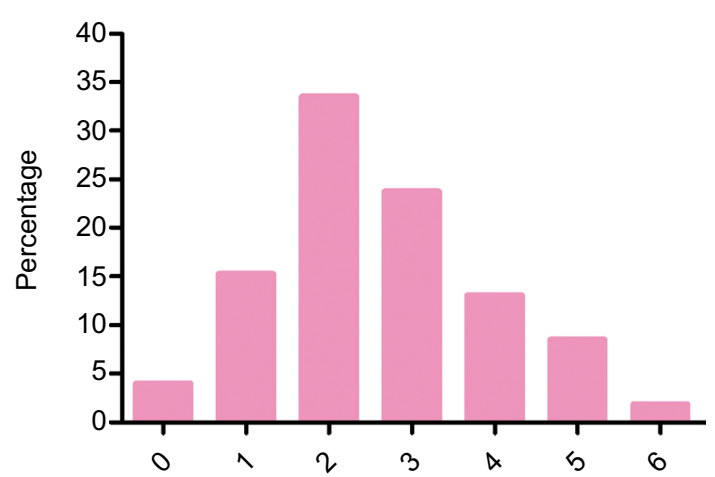

C

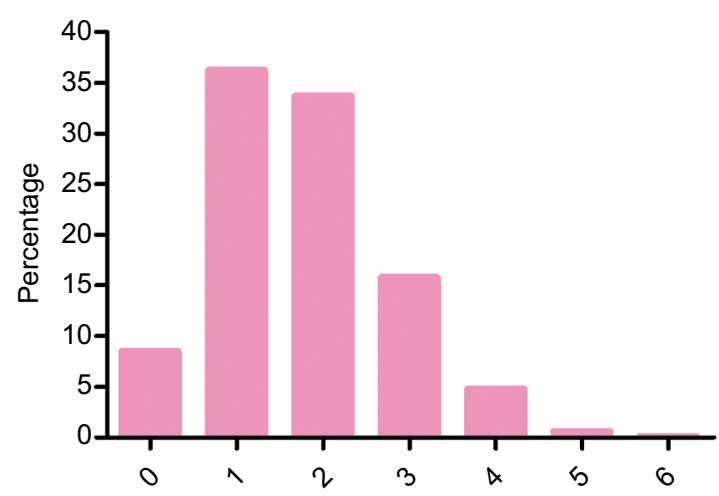

B

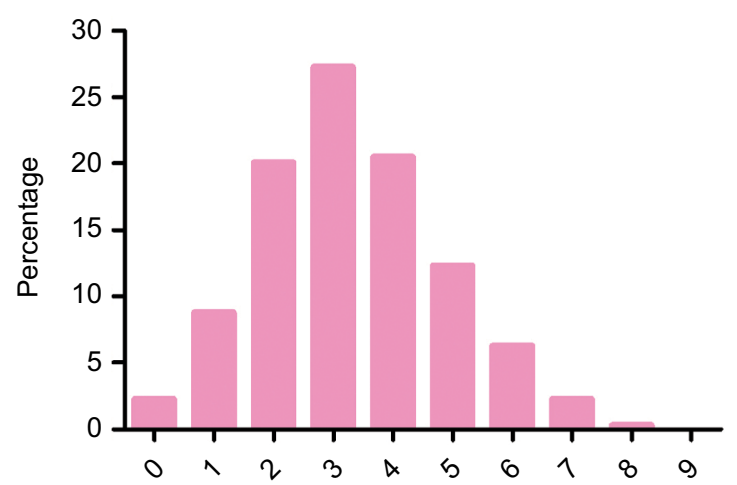

D

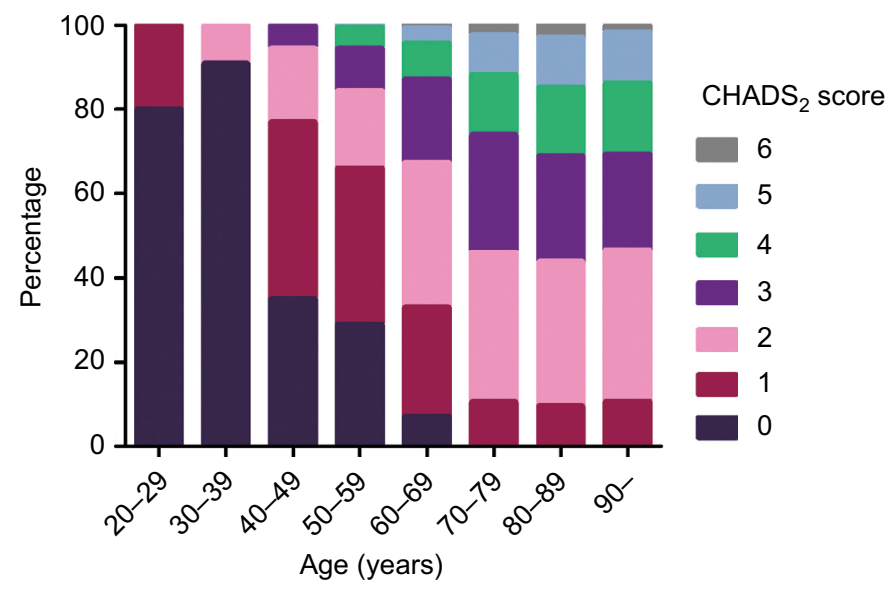

E

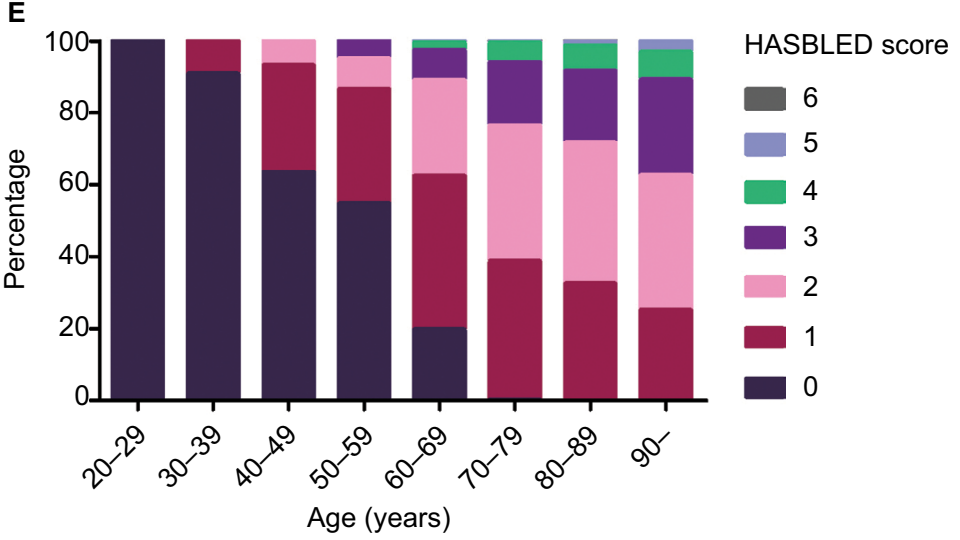

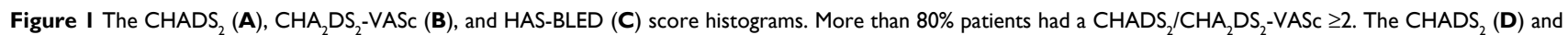
HAS-BLED scores (E) increased with age.

Also, we observed a growing tendency for the $\mathrm{CHADS}_{2}$ score and HAS-BLED score with increasing age, with patients having a $\mathrm{CHADS}_{2}$ score $\geq 2$ accounting for $>80 \%$ of the elderly patients ( $\geq 70$ years old).

\section{Antithrombotic treatment patterns for stroke prevention}

Figure 2A and B shows the relationship between stroke risk classification and anticoagulant treatment. According to the $\mathrm{CHADS}_{2}$ score, $4.0 \%$ of the patients were stratified into the low risk, $15.3 \%$ into the moderate risk, and $80.7 \%$ into the high-risk groups. OACs (including warfarin and non-vitamin $\mathrm{K}$ antagonist oral anticoagulants [NOACs]) were only prescribed to $11.5 \%$ of the 3055 patients with a high risk of stroke $\left(\mathrm{CHADS}_{2} \geq 2\right)$, whereas antiplatelet drugs (including aspirin, clopidogrel, cilostazol, or dual antiplatelet) were prescribed to more than half of the patients. Aspirin was the most frequently prescribed drug 
A
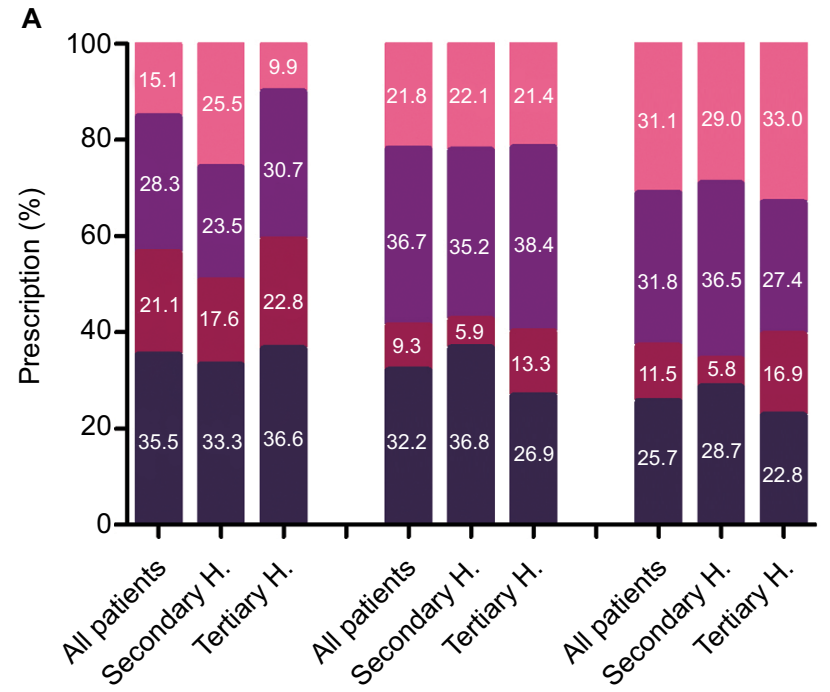

$\mathrm{CHADS}_{2}=0$

$\mathrm{CHADS}_{2}=1$

$\mathrm{CHADS}_{2} \geq 2$

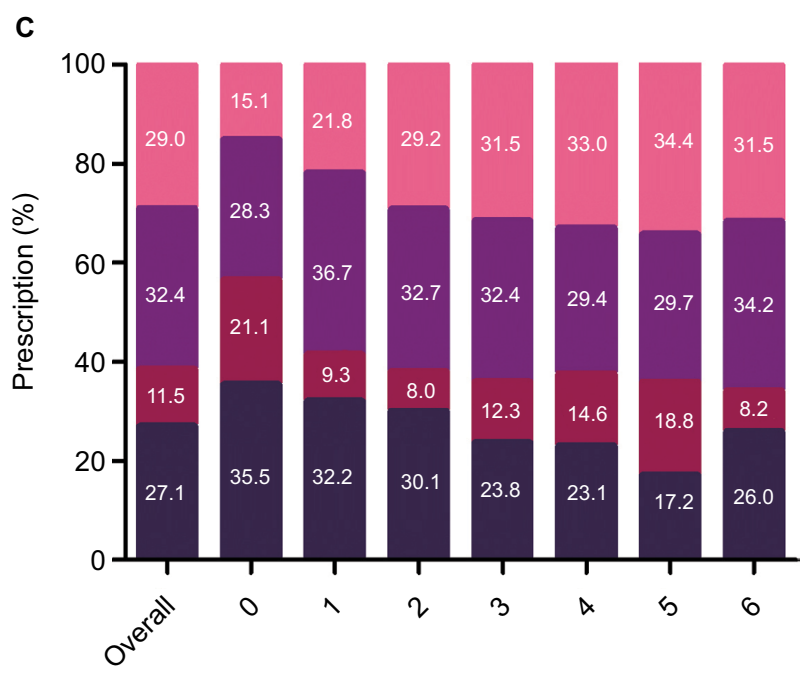

$\mathrm{CHADS}_{2}$ score

\section{B}
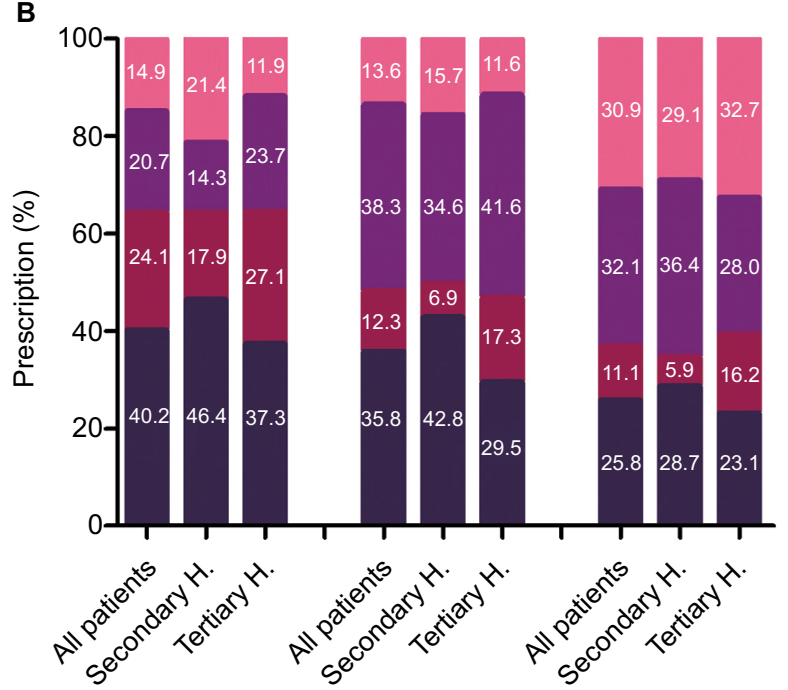

$\mathrm{CHA}_{2} \mathrm{DS}_{2}-\mathrm{VASc}=0 \quad \mathrm{CHA}_{2} \mathrm{DS}_{2}-\mathrm{VASc}=1 \quad \mathrm{CHA}_{2} \mathrm{DS}_{2}-\mathrm{VASc} \geq 2$

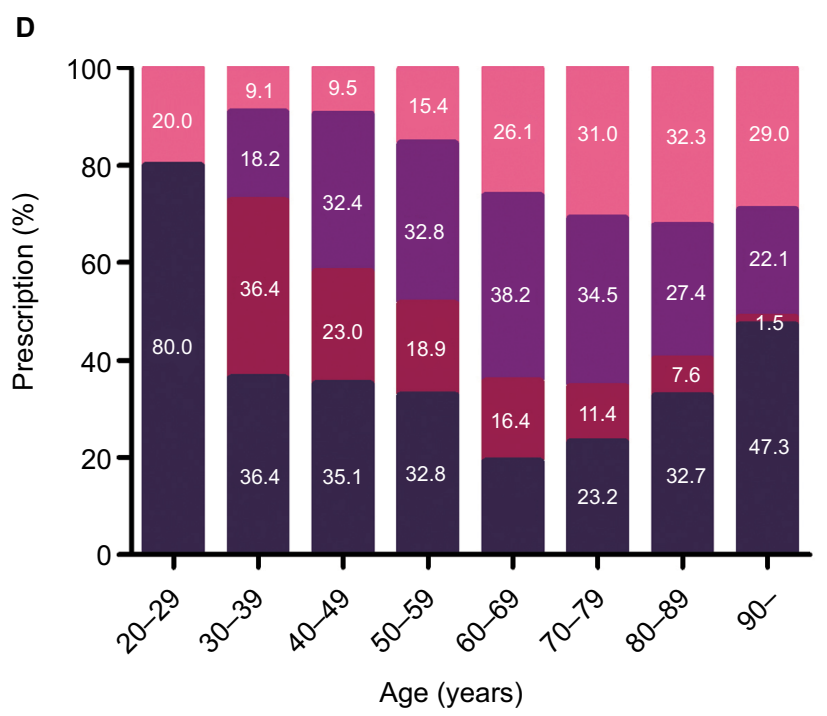

Figure 2 Differences in the antithrombotic strategy for stroke prevention according to the $\mathrm{CHADS}_{2}$ score $(\mathbf{A})$ and $\mathrm{CHA}_{2} \mathrm{DS}_{2}-\mathrm{VASc}$ score $(\mathbf{B})$ between the secondary and tertiary hospitals. For patients with $\mathrm{CHADS}_{2} \geq 2$, the OAC use rate in the secondary hospitals was significantly lower than the rate in the tertiary hospitals ( $\left.<<0.00 \mathrm{I}\right)$. The distribution of antithrombotic drugs according to the $\mathrm{CHADS}_{2}$ scores (C) showed that the proportion of anticoagulant therapy did not increase with the $\mathrm{CHADS}_{2}$ score. Antithrombotic drug use in the different age groups (D) showed that OAC was rarely prescribed to the elderly patients. Others indicate clopidogrel, cilostazol, lowmolecular weight heparin, and fondaparinux sodium; secondary $\mathrm{H}$. indicates the secondary hospitals; and tertiary $\mathrm{H}$. indicates the tertiary hospitals.

Abbreviation: OAC, oral anticoagulation.

for stroke prevention for AF patients in our study. However, $25.7 \%$ of the high-risk patients did not receive any antithrombotic treatment. In the low-risk group $\left(\mathrm{CHADS}_{2}=0\right)$, the treatment rate with an anticoagulant was as high as $21.1 \%$. Overall, the proportion of anticoagulant therapy did not correspondingly increase with the increase in the $\mathrm{CHADS}_{2}$ score (Figure 2C). Furthermore, the percentage of anticoagulation therapy decreased with advancing age
(Figure 2D). Among the elderly patients ( $\geq 80$ years), the OAC use rate was only $7.0 \%$.

\section{NVAF patients in the secondary hospitals} vs. NVAF patients in the tertiary hospitals Among all NVAF inpatients, 48.7\% (1842/3785) came from secondary hospitals and 51.3\% (1943/3785) came from tertiary hospitals. Table 2 shows the comparison of 
Table 2 NVAF patients in secondary hospitals vs. NVAF patients in tertiary hospitals

\begin{tabular}{|c|c|c|c|}
\hline Variable & $\begin{array}{l}\text { Secondary } \\
\text { hospitals } \\
(n=1842)\end{array}$ & $\begin{array}{l}\text { Tertiary } \\
\text { hospitals } \\
(n=1943)\end{array}$ & $P$-value \\
\hline \multicolumn{4}{|l|}{ CHADS $_{2}$ score } \\
\hline Mean \pm SD & $2.53 \pm 1.26$ & $2.66 \pm I .4 I$ & 0.003 \\
\hline 0 & $5 \mathrm{I}(2.8)$ & 101 (5.2) & \\
\hline I & $307(16.7)$ & $27 \mid(13.9)$ & \\
\hline$\geq 2$ & I $484(80.6)$ & I57| (80.9) & 0.821 \\
\hline \multicolumn{4}{|c|}{$\mathrm{CHA}_{2} \mathrm{DS}_{2}-\mathrm{VASc}$ score } \\
\hline Mean \pm SD & $3.25 \pm 1.46$ & $3.35 \pm 1.61$ & 0.03 \\
\hline 0 & $28(1.5)$ & $59(3.0)$ & \\
\hline I & $159(8.6)$ & $173(8.9)$ & \\
\hline$\geq 2$ & $1655(89.8)$ & $1711(88.1)$ & \\
\hline \multicolumn{4}{|l|}{ HAS-BLED score } \\
\hline Mean \pm SD & $1.70 \pm 0.98$ & $1.80 \pm 1.09$ & 0.007 \\
\hline$<3$ & $1497(81.3)$ & 1475 (75.9) & \\
\hline$\geq 3$ & $345(18.7)$ & $468(24.1)$ & \\
\hline \multicolumn{4}{|c|}{ Anticoagulant strategy } \\
\hline None & $556(30.2)$ & $468(24.1)$ & $<0.001$ \\
\hline OAC & $113(6.1)$ & $324(16.7)$ & $<0.001$ \\
\hline Warfarin & $113(6.1)$ & $320(16.5)$ & $<0.001$ \\
\hline $\begin{array}{l}\text { Factor } \mathrm{Xa} / \text { direct } \\
\text { thrombin inhibitor }\end{array}$ & $0(0)$ & $4(0.2)$ & \\
\hline Aspirin & $661(35.9)$ & $565(29.1)$ & $<0.001$ \\
\hline Others ${ }^{a}$ & $512(27.8)$ & $586(30.2)$ & \\
\hline \multicolumn{4}{|l|}{ INR } \\
\hline Mean \pm SD & $1.79 \pm 0.93$ & $1.44 \pm 0.60$ & 0.001 \\
\hline$<1.50$ & $19(46.3)$ & $209(67.9)$ & \\
\hline $1.50-1.99$ & II (26.3) & $48(15.6)$ & \\
\hline $2.00-3.00$ & $8(19.5)$ & 39 (12.7) & 0.227 \\
\hline$>3.00$ & $3(7.3)$ & $12(3.9)$ & \\
\hline
\end{tabular}

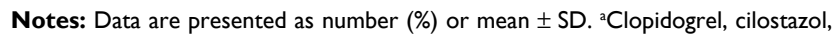
low-molecular-weight heparin, fondaparinux sodium.

Abbreviations: INR, international normalized ratio; NVAF, nonvalvular atrial fibrillation; OAC, oral anticoagulant; SD, standard deviation.

antithrombotic treatment for NVAF patients in the secondary and tertiary hospitals. The mean $\mathrm{CHADS}_{2}$ score was significantly different between the secondary and tertiary hospitals ( $2.53 \pm 1.26$ vs. $2.66 \pm 1.41, P=0.003)$. The antithrombotic strategy was also different between the two types of hospitals. OAC was less prescribed in the secondary hospitals than in the tertiary hospitals $(6.1 \%$ vs. $16.7 \%, P<0.001)$, and the percentage of patients who received no antithrombotic drugs in the secondary hospitals was higher than the percentage in the tertiary hospitals $(30.2 \%$ vs. $24.1 \%, P<0.001)$.

The percentages of patients with $\mathrm{CHADS}_{2} \geq 2$ were similar between the two different hospital levels ( $80.6 \%$ vs. $80.9 \%, P=0.821)$. However, the use of anticoagulant therapy remained markedly different between these patients, who should receive anticoagulation therapy according to the guidelines (Figure 2A and B). Compared with the tertiary hospitals, the secondary hospitals gave priority to aspirin
Table 3 Main reasons why warfarin was not prescribed to NVAF patients with $\mathrm{CHADS}_{2} \geq 2$

\begin{tabular}{|c|c|c|c|}
\hline Reasons & $\begin{array}{l}\text { All } \\
\text { patients } \\
(\mathrm{N}=\mathbf{2 7 0 4})\end{array}$ & $\begin{array}{l}\text { Secondary } \\
\text { hospitals } \\
(n=1398)\end{array}$ & $\begin{array}{l}\text { Tertiary } \\
\text { hospitals } \\
(n=1306)\end{array}$ \\
\hline Patient refusal & $258(9.5)$ & $87(6.2)$ & $17 \mid(13.1)$ \\
\hline Physician's choice & 2094 (77.4) & II8I (84.5) & $913(69.9)$ \\
\hline $\begin{array}{l}\text { Already taking other } \\
\text { anticoagulants drugs for } \\
\text { other medical conditions }\end{array}$ & $110(4.1)$ & $52(3.7)$ & $58(4.4)$ \\
\hline $\begin{array}{l}\text { Taking medication is } \\
\text { contraindicated }\end{array}$ & $242(8.9)$ & $78(5.6)$ & $164(12.6)$ \\
\hline
\end{tabular}

( $36.5 \%$ vs. $27.4 \%, P<0.001)$ to prevent stroke and rarely prescribed OACs $(5.8 \%$ vs. $16.9 \%, P<0.001)$.

\section{Reasons for the underuse of warfarin}

Table 3 shows the reasons for the underuse of warfarin, including patient refusal (9.5\%), physician's choice (77.4\%), already taking other anticoagulant drugs for other medical conditions (4.1\%), and contraindication for taking medicines (8.9\%).

\section{Discussion}

This cross-sectional study investigated the use of anticoagulant therapy in Southwest China. The results demonstrated that the prescription of anticoagulation drugs were highly insufficient for hospitalized NVAF patients. Only 9.3\% (351/3785) of the NVAF patients who received anticoagulant therapy were prescribed the correct anticoagulation agents according to the $\mathrm{CHADS}_{2}$ score system recommended by the 2011 American College of Cardiology Foundation/American Heart Association and Heart Rhythm Society guidelines. ${ }^{11}$ This study showed a large space for the improvement of stroke prevention for the Chinese population and demonstrated that an effective prevention system is urgently needed to improve anticoagulation therapy in NVAF patients.

One of the most important findings of this study is that the underuse of anticoagulant therapy in NVAF patients is more serious than we thought in Southwest China, especially in the secondary hospitals. According to a nationwide survey of hospitalized AF patients in mainland China carried out in 2004 , only $6.6 \%$ of these patients received warfarin, $57.9 \%$ had antiplatelet therapy, and $35.5 \%$ did not receive any antithrombotic therapy. ${ }^{12}$ Although the overall proportion of antithrombotic therapy $(72.9 \%)$ and anticoagulation therapy (11.5\%) obviously increased in Southwestern China over the past 10 years, it is still far behind Eastern China and other countries. Liu et al's study enrolled 2220 NVAF patients 
at six tertiary hospitals located in three of the most developed cities of China and found the percentages of patients receiving warfarin, aspirin, or no antithrombotic regimen to be $31 \%, 21 \%$, and $17 \%$, respectively. ${ }^{13}$ The Fushimi AF Registry was a community-based survey of AF patients in Japan that enrolled 3183 patients from March 2011 to June $2012 .{ }^{8}$ In this study, warfarin was prescribed for $48.5 \%$ of the patients. A retrospective cohort study of inpatients with NVAF showed 54\% used warfarin; this study was performed at 21 teaching hospitals, 13 community hospitals, and 4 veteran administration hospitals in the USA. ${ }^{14}$ Moreover, the PREFER in AF registry (Prevention of thromboembolic events - European Registry in Atrial Fibrillation), ${ }^{15}$ which enrolled 7243 patients in seven representative European countries, showed that $>80 \%$ of AF patients received OAC and that $85.6 \%$ of patients with a $\mathrm{CHA}_{2} \mathrm{DS}_{2}$-VASc score $\geq 2$ were prescribed OAC. In light of these data, the deficiency of anticoagulant administration to NVAF patients in Southwestern China is obvious.

Even worse, anticoagulation is not only underused, but also misused. First, there was no significant difference in anticoagulant therapy in patients with different risk scores and warfarin was overused in patients at low risk $\left(\mathrm{CHADS}_{2}=0\right)$. We speculate that most patients' anticoagulant strategies were not prescribed in accordance with the guidelines. Second, to circumvent the risk of bleeding, antiplatelet drugs (especially aspirin) were overused to replace clinical anticoagulant agents. Studies have shown that aspirin is far less powerful than warfarin in preventing stroke in $\mathrm{AF}$ patients. ${ }^{4}$ Dual antiplatelet therapy, such as clopidogrel plus aspirin, had an increased bleeding risk, but was still less effective than warfarin. ${ }^{16,17}$

Elderly AF patients ( $\geq 80$ years) were less likely to receive OACs in this study. In the USA, only $30 \%$ of older AF patients received anticoagulation therapy, which was much less than the rate in younger patients. Thus, underused anticoagulant therapy in older AF patients is a global problem. However, the Birmingham Atrial Fibrillation Treatment of the Aged Study trial (BAFTA) confirmed the superiority of warfarin over aspirin in reducing the risk of ischemic stroke in AF patients aged $\geq 75$ years without an increase in major bleeding events. ${ }^{18}$ Aspirin therapy is limited in older patients because the efficacy of aspirin seems to decline beyond the age of 70 years, whereas the risk of bleeding increases. ${ }^{19}$ Therefore, age is not a contraindication to anticoagulation and warfarin should be more prescribed in older AF patients to prevent stroke.

The underutilization of anticoagulant therapy for NVAF patients is a common phenomenon. However, the factors that lead to the poor warfarin prescription rates are unknown. This study demonstrated that physician's choice was the most important reason, followed by patient refusal. A large number of doctors lacked knowledge concerning the management of AF and knew less about anticoagulation therapy. ${ }^{20}$ Also, the majority of physicians feared the bleeding risk related to warfarin, which was likely to lead to conflicts between doctors and patients. ${ }^{21,22}$ However, previous studies reported that the lack of knowledge concerning AF in patients who do not understand the risks and/or benefits of anticoagulant therapy led to their poor compliance and bad disease selfmanagement. ${ }^{23-27}$ Other reasons, such as frequently monitoring INR, no specialized anticoagulation clinic, and economic considerations, also contributed to the underuse of warfarin. Taken together, the underutilization of warfarin was strongly related to the lack of an effective management system and concerns about security. Recently, NOACs, including dabigatran, rivaroxaban, apixaban, and edoxaban, have changed the landscape of thromboprophylaxis for ischemic stroke due to their effective stroke prevention and removal of the need to monitor INR. ${ }^{28}$ However, in this study, only four patients who had a high risk of stroke and bleeding were prescribed NOACs. The expensive prices of NOACs make them unaffordable for most Chinese patients because they are not covered by health care insurance. Thus, although NOACs are attractive alternatives, warfarin will most likely continue to be used in China for many AF patients.

Anticoagulation is a lifelong treatment for patients with $\mathrm{AF}$, but the sharp contrast between the guidelines and reality is thought provoking. We need to do a great deal more to improve this bad situation. First, we should strengthen doctor training programs on coagulation management of AF, improve patient-physician communication, and add a post-discharge phone call follow-up. Second, educational intervention for AF patients is necessary to raise their awareness of anticoagulation treatment. Also, establishing specialized anticoagulation clinics for easy follow-up or developing mobile medical apps for ease of management may be helpful. Finally, AF should be brought into the scope of coverage, which will lighten the financial burden caused by monitoring INR or NOACs.

\section{Limitations}

There are several limitations to be addressed in the present study. This study was conducted only in secondary and tertiary hospitals and not in primary hospitals; thus, the representativeness of the sample is limited. However, because first-level hospitals are rarely responsible for the diagnosis and treatment 
of AF in China, we speculate that not including these hospitals in this study did not lead to a serious bias in the sample. Next, this study is a hospital-based study instead of a populationbased study and, therefore, may miss many undiagnosed or out-of-hospital AF patients; thus, the data in the real world may be even worse. Finally, we did not record the reasons why patients refused to take warfarin or why doctors refused to prescribe warfarin in detail, which hampered the analysis of the causes of the deficiency in anticoagulant use.

\section{Conclusion}

After our comprehensive study of hospitalized AF patients in Southwest China, we demonstrated that NVAF inpatients received a lower level of anticoagulation drugs for stroke prevention than the national level. Anticoagulation therapy was not only underused, but also incorrectly used. Risk stratification and the guidepost for treatment in international guidelines had little effect on warfarin use. According to the China National Stroke Registry, ${ }^{29}$ inadequate anticoagulant therapy in patients with AF is one reason for the high incidence of stroke in China. Consequently, immediate steps, such as strengthening doctor training, improving the quality of doctor-patient communication, and launching patient's health education initiatives, are urgently needed to promote the prophylaxis of thromboembolism in China.

\section{Acknowledgments}

We thank the following institutions for their cooperation: The First Affiliated Hospital of Chongqing Medical University, The Third People's Hospital of Chongqing, The Fifth People's Hospital of Chongqing, The Ninth People's Hospital of Chongqing, Yongchuan Hospital of Chongqing Medical University, Changshou District People's Hospital, Jiangjin District People's Hospital, Chongqing Three Gorges Central Hospital, Zhongshan Hospital of Chongqing, The Eighth People's Hospital of Chongqing, Banan District People's Hospital, Jiangbei District People's Hospital, Hechuan District People's Hospital, Chang'an Hospital of Chongqing, Bishan County People's Hospital, Qijiang County People's Hospital, Kaixian County People's Hospital, Liangping County People's Hospital, Dazu County People's Hospital, Chonggang Hospital, and University-Town Hospital of Chongqing Medical University.

\section{Author contributions}

All authors contributed toward research design, data collection, data analysis, drafting, and critically revising the paper and agree to be accountable for all aspects of the work.

\section{Disclosure}

The authors report no conflicts of interest in this work.

\section{References}

1. Lip GY, Brechin CM, Lane DA. The global burden of atrial fibrillation and stroke: a systematic review of the epidemiology of atrial fibrillation in regions outside North America and Europe. Chest. 2012;142(6): 1489-1498.

2. Zhou ZQ, Hu DY, Chen J, Zhang RH, Li KB, Zhao XL. [An epidemiological survey of atrial fibrillation in China]. Zhonghua Nei Ke Za Zhi. 2004;43(7):491-494. Abstract in English.

3. Wolf PA, Dawber TR, Thomas HE Jr, Kannel WB. Epidemiologic assessment of chronic atrial fibrillation and risk of stroke: the Framingham study. Neurology. 1978;28(10):973-977.

4. Hart RG, Pearce LA, Aguilar MI. Meta-analysis: antithrombotic therapy to prevent stroke in patients who have nonvalvular atrial fibrillation. Ann Intern Med. 2007;146(12):857-867.

5. van Walraven C, Hart RG, Singer DE, et al. Oral anticoagulants vs aspirin in nonvalvular atrial fibrillation: an individual patient metaanalysis. JAMA. 2002;288(19):2441-2448.

6. Risk factors for stroke and efficacy of antithrombotic therapy in atrial fibrillation. Analysis of pooled data from five randomized controlled trials. Arch Intern Med. 1994;154(13):1449-1457.

7. Sun Y, Hu D; Chinese Investigators of GARFIELD; Chinese Investigators of GARFIELD. [Chinese subgroup analysis of the global anticoagulant registry in the FIELD (GARFIELD) registry in the patients with non-valvular atrial fibrillation]. Zhonghua Xin Xue Guan Bing Za Zhi. 2014;42(10):846-850. Chinese.

8. Akao M, Chun YH, Wada H, et al; Fushimi AF Registry Investigators. Current status of clinical background of patients with atrial fibrillation in a community-based survey: the Fushimi AF Registry. J Cardiol. 2013; 61(4):260-266.

9. Nieuwlaat R, Capucci A, Camm AJ, et al; European Heart Survey Investigators. Atrial fibrillation management: a prospective survey in ESC member countries: the Euro Heart Survey on Atrial Fibrillation. Eur Heart J. 2005;26(22):2422-2434.

10. Ogilvie IM, Newton N, Welner SA, Cowell W, Lip GY. Underuse of oral anticoagulants in atrial fibrillation: a systematic review. Am J Med. 2010;123(7):638-645.e4.

11. Fuster V, Ryden LE, Cannom DS, et al. 2011 ACCF/AHA/HRS focused updates incorporated into the ACC/AHA/ESC 2006 guidelines for the management of patients with atrial fibrillation: a report of the American College of Cardiology Foundation/American Heart Association Task Force on Practice Guidelines developed in partnership with the European Society of Cardiology and in collaboration with the European Heart Rhythm Association and the Heart Rhythm Society. J Am Coll Cardiol. 2011;57(11):e101-e198.

12. Wen-Hang QI; Society of Cardiology, Chinese Medical Association. Retrospective investigation of hospitalised patients with atrial fibrillation in mainland China. Int J Cardiol. 2005;105(3):283-287.

13. Liu B, Liu LZ, Xuan J, et al. Treatment patterns associated with stroke prevention in patients with atrial fibrillation in three major cities in the People's Republic of china. Int J Gen Med. 2013;7:29-35.

14. Waldo AL, Becker RC, Tapson VF, Colgan KJ; NABOR Steering Committee. Hospitalized patients with atrial fibrillation and a high risk of stroke are not being provided with adequate anticoagulation. J Am Coll Cardiol. 2005;46(9):1729-1736.

15. Kirchhof P, Ammentorp B, Darius H, et al. Management of atrial fibrillation in seven European countries after the publication of the 2010 ESC Guidelines on atrial fibrillation: primary results of the PREvention oF thromboemolic events-European Registry in Atrial Fibrillation (PREFER in AF). Europace. 2014;16(1):6-14.

16. Connolly S, Pogue J, Hart R, et al. Clopidogrel plus aspirin versus oral anticoagulation for atrial fibrillation in the Atrial fibrillation Clopidogrel Trial with Irbesartan for prevention of Vascular Events (ACTIVE W): a randomised controlled trial. Lancet. 2006;367(9526):1903-1912. 
17. Connolly SJ, Pogue J, Hart RG, et al; ACTIVE Investigators. Effect of clopidogrel added to aspirin in patients with atrial fibrillation. $N \mathrm{Engl}$ J Med. 2009;360(20):2066-2078.

18. Mant J, Hobbs FD, Fletcher K, et al; BAFTA investigators; Midland Research Practices Network (MidReC). Warfarin versus aspirin for stroke prevention in an elderly community population with atrial fibrillation (the Birmingham Atrial Fibrillation Treatment of the Aged Study, BAFTA): a randomised controlled trial. Lancet. 2007;370(9586): 493-503.

19. van Walraven C, Hart RG, Connolly S, et al. Effect of age on stroke prevention therapy in patients with atrial fibrillation: the atrial fibrillation investigators. Stroke. 2009;40(4):1410-1416.

20. Lee VW, Tam CS, Yan BP, Man YC, Yin LY. Barriers to warfarin use for stroke prevention in patients with atrial fibrillation in Hong Kong. Clin Cardiol. 2013;36(3):166-171.

21. Choudhry NK, Anderson GM, Laupacis A, Ross-Degnan D, Normand SL, Soumerai SB. Impact of adverse events on prescribing warfarin in patients with atrial fibrillation: matched pair analysis. BMJ. 2006;332(7534): 141-145.

22. Man-Son-Hing M, Laupacis A. Anticoagulant-related bleeding in older persons with atrial fibrillation: physicians' fears often unfounded. Arch Intern Med. 2003;163(13):1580-1586.
23. Fuller R, Dudley N, Blacktop J. Risk communication and older peopleunderstanding of probability and risk information by medical inpatients aged 75 years and older. Age Ageing. 2001;30(6):473-476.

24. Kagansky N,KnoblerH, RimonE, OzerZ, Levy S. Safety of anticoagulation therapy in well-informed older patients. Arch Intern Med. 2004;164(18): 2044-2050.

25. Kimmel SE, Chen Z, Price M, et al. The influence of patient adherence on anticoagulation control with warfarin: results from the International Normalized Ratio Adherence and Genetics (IN-RANGE) Study. Arch Intern Med. 2007;167(3):229-235.

26. Lane DA, Ponsford J, Shelley A, Sirpal A, Lip GY. Patient knowledge and perceptions of atrial fibrillation and anticoagulant therapy: effects of an educational intervention programme. The West Birmingham Atrial Fibrillation Project. Int J Cardiol. 2006;110(3):354-358.

27. Miller NH. Compliance with treatment regimens in chronic asymptomatic diseases. Am J Med. 1997;102(2A):43-49.

28. RuffCT, Giugliano RP, Braunwald E, et al. Comparison of the efficacy and safety of new oral anticoagulants with warfarin in patients with atrial fibrillation: a meta-analysis of randomised trials. Lancet. 2014;383(9921):955-962.

29. Wang Y, Cui L, Ji X, et al. The China National Stroke Registry for patients with acute cerebrovascular events: design, rationale, and baseline patient characteristics. Int J Stroke. 2011;6(4):355-361.
International Journal of General Medicine

\section{Publish your work in this journal}

The International Journal of General Medicine is an international, peer-reviewed open-access journal that focuses on general and internal medicine, pathogenesis, epidemiology, diagnosis, monitoring and treatment protocols. The journal is characterized by the rapid reporting of reviews, original research and clinical studies across all disease areas.

\section{Dovepress}

The manuscript management system is completely online and includes a very quick and fair peer-review system, which is all easy to use. Visit http://www.dovepress.com/testimonials.php to read real quotes from published authors.

Submit your manuscript here: https://www.dovepress.com/international-journal-of-general-medicine-journal 